\title{
Flexion Gap Measured in 45 Degrees and 90 Degrees of Hip Flexion Positions during Total Knee Arthroplasty: Measurement by Navigation System
}

\author{
Jin Kyu Lee, MD, Kyu-Sung Chung, MD, Bo-Hyun Kim, MD, and Choong Hyeok Choi, MD \\ Department of Orthopaedic Surgery, Hanyang University College of Medicine, Seoul, Korea
}

\begin{abstract}
Purpose: To evaluate the influence of thigh weight in different hip flexion positions on the knee flexion gap in total knee arthroplasty (TKA). Materials and Methods: We evaluated 20 patients ( 25 knees) with osteoarthritis of the knee that underwent TKA using a navigation system from May 2010 to April 2011. After posterior cruciate ligament sacrificing, complete soft tissue balancing, and fixation of all components with cement, the flexion gaps were measured with the patello-femoral joint reduced. Medial and lateral flexion gaps were measured separately in both the $90^{\circ}-90^{\circ}$ and $45^{\circ}-90^{\circ}$ flexion positions of the hip-knee joints.

Results: The medial and lateral flexion gaps in the $45^{\circ}-90^{\circ}$ flexion position of the hip-knee joints were $13.02 \pm 2.17 \mathrm{~mm}$ and $13.12 \pm 2.21 \mathrm{~mm}$, respectively. The medial and lateral flexion gaps in the $90^{\circ}-90^{\circ}$ flexion position were $12.92 \pm 2.03 \mathrm{~mm}$ and $13.08 \pm 2.29 \mathrm{~mm}$, respectively. The flexion gaps showed no significant ( $\mathrm{p}>0.05)$ differences between the two different hip flexion positions.

Conclusions: Flexion gaps in TKA were not influenced by hip flexion positions ( $45^{\circ}$ or $90^{\circ}$ of flexion). Therefore, soft tissue balancing and polyethylene thickness should not be affected by hip flexion positions during TKA.
\end{abstract}

Keywords: Knee, Arthroplasty, Navigation, Hip joint position, Flexion gap

\section{Introduction}

An essential principle in total knee arthroplasty (TKA) is soft tissue balance that is obtained by symmetrical medial and lateral flexion-extension gaps in the coronal plane ${ }^{1-3}$. Proper bone resection and soft tissue balance are required to create adequate joint spaces determined, in general, by the size of flexion and extension gaps in $90^{\circ}$ knee flexion ${ }^{4,5}$.

It has been traditionally perceived that the extension gap of the knee should be assessed with both the hip and knee in neutral

Received December 31, 2013; Revised (1st) February 25, 2014;

(2nd) March 11, 2014; Accepted March 14, 2014

Correspondence to: Choong Hyeok Choi, MD

Department of Orthopaedic Surgery, Hanyang University College of Medicine, 222, Wangsimni-ro, Seongdong-gu, Seoul 133-791, Korea

Tel: +82-2-2290-8485, Fax: +82-2-2299-3774

E-mail: chhchoi@hanyang.ac.kr

This is an Open Access article distributed under the terms of the Creative Commons Attribution Non-Commercial License (http://creativecommons.org/licenses/by-nc/3.0/) which permits unrestricted non-commercial use, distribution, and reproduction in any medium, provided the original work is properly cited. position. In contrast, there is room for controversy regarding the optimal hip flexion position for accurate measurement of the flexion gap of the knee. This is because tension of the adjacent soft tissues, including the iliotibial band and the quadriceps muscle, deemed affected by the hip flexion position and the weight of the thigh may have an influence on the knee joint space.

The purpose of this study was to investigate the impact of different hip-knee flexion positions $\left(45^{\circ}-90^{\circ}\right.$ vs. $\left.90^{\circ}-90^{\circ}\right)$ on the flexion gap of the knee in TKA using a navigation system for measurements. Our hypothesis was that the flexion gap would be significantly reduced when the hip is in $45^{\circ}$ of flexion due to the thigh weight.

\section{Materials and Methods}

Of the patients who underwent primary TKA for osteoarthritis of the knee at our institution between May 2010 and April 2011, those who had navigation-assisted TKA and gave consent for participation were included in the study. The exclusion criteria were the presence of a disorder other than osteoarthritis, a history of prior surgery, $<90^{\circ}$ of preoperative range of motion, $\geq 20^{\circ}$ 
of varus-valgus deformity, and anteroposterial or mediolateral instability in the operated knee. In the total study population, there were 25 knees (11 left and 14 right knees) in 20 patients ( 4 males and 16 females). Their mean age at the time of surgery was 66.9 years (range, 53 to 76 years) and the mean body mass index was $26.07 \mathrm{~kg} / \mathrm{m}^{2}$ (range, 21.33 to $28.48 \mathrm{~kg} / \mathrm{m}^{2}$ ).

TKA was performed using a posterior cruciate ligament (PCL) substituting PFC Sigma knee system (DePuy Orthopedics, Warsaw, IN, USA) under the navigational guidance of Ci knee essential system (DePuy Orthopedics) in all patients.

All the operations were performed by the same surgeon using a medial parapatellar approach with the hip and knee joints placed in $45^{\circ}$ flexion position and a tourniquet applied. After joint exposure, infrared camera trackers were anchored to the distal femur and the anteromedial aspect of the proximal tibia, and the center of the hip located through rotational exercises was registered. Subsequently, locations of the anatomical structures in the femur and tibia were registered using a probe in the $\mathrm{Ci}$ knee system. Under the guidance of the Ci knee system using the gap technique, tibial resection was performed with the goal of creating $0^{\circ}$ of varus-valgus angulation in the coronal plane and $4^{\circ}$ of posterior slope in the sagittal plane. Femoral resection was performed to make the anatomical axis be in $6^{\circ}$ valgus relative to the mechanical axis. With a trial prosthesis positioned in place, the mechanical axis of the lower limb, extension and flexion gap balance, and medial-lateral soft-tissue balance were assessed using navigation system. When proper bone resection and soft-tissue balance were considered achieved, the thickness of the polyethylene insert was determined according to the size of the extension gap and the flexion gap measured with the hip in $45^{\circ}$ flexion. The implants were fixed using bone cement. Patella tracking was confirmed with the patella reduced using the no thumb technique. Lateral retinacular release was not considered necessary in any of the cases. After tourniquet release, with the patella reduced, medial and lateral flexion-extension gaps and midflexion gaps
( $45^{\circ}$ of knee flexion position) were measured with the hip in $90^{\circ}$ flexion and $45^{\circ}$ flexion each using navigation system (Fig. 1). The distances from the proximal tibial cut surface to a site inferior to the femoral component (extension gap) and to the posterior border of the femoral component (flexion gap) were measured using a navigation probe without additional application of traction. Values measured in $0.5 \mathrm{~mm}$ increments were recorded for analysis when three orthopedic surgeons agreed on the flexion angles of the hip and knee joints and knee joint gaps presented on the navigation screen.

Factors that may be associated with the flexion gap, including joint line elevation, femoral component rotation, and mechanical axis deviation (MAD) were assessed: the joint line height from tibial tuberosity (JLHT), patellar tilt angle (PTA), and MAD were measured on the preoperative, postoperative, and 6-month postoperative radiographs. The preoperative JLHT was defined as the distance from the upper margin of the tibial tuberosity to the tibial plateau on the preoperative lateral radiograph and the postoperative JLHT to the lower margin of the femoral component on the postoperative radiograph ${ }^{6}$. The PTA was defined as the angle created by a line connecting the medial and lateral borders of the patella and a line connecting the most anteriorly protruding portions of the medial and lateral condyles of the femur on the merchant view ${ }^{7)}$. The MAD was measured as the angle between the mechanical axis connecting the centers of the femoral head and the ankle and the anatomical axis of the tibia on the weight-bearing long-leg anteroposterior radiograph ${ }^{8)}$, and a varus angle was assigned a negative value whereas a valgus angle was designated a positive value.

Statistical analyses were performed using SPSS ver. 18.0 (SPSS Inc., Chicago, IL, USA). The differences in joint gaps according to hip flexion positions and the preoperative and postoperative radiographic findings were evaluated using paired t-test with significance set at $\mathrm{p}<0.05$.
A

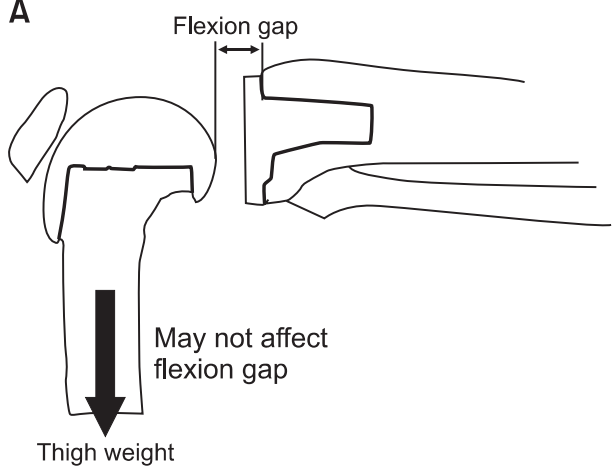

B

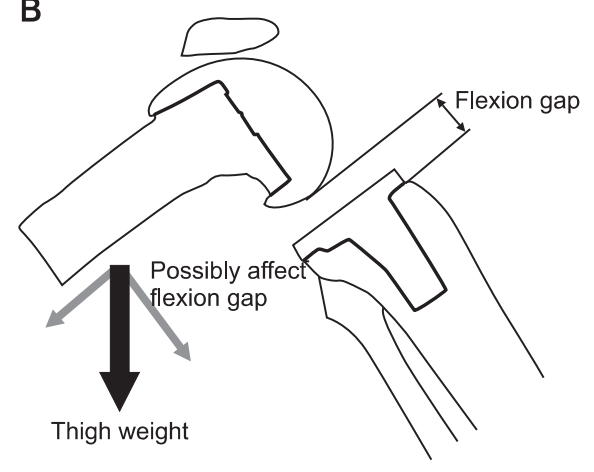

Fig. 1. Schematic representation of flexion gap measurement. When the hip is in $90^{\circ}$ flexion, the weight of the thigh may not affect the flexion gap (A). When the hip is in $45^{\circ}$ flexion, the weight of the thigh would possibly affect the flexion gap (B). 


\section{Results}

Regarding the joint gap measurements using navigation system, the mean extension gap was $12.90 \pm 1.70 \mathrm{~mm}$ on the medial side and $13.28 \pm 1.70 \mathrm{~mm}$ on the lateral side. The mean midflexion gap measured with the knee in $45^{\circ}$ flexion was $12.98 \pm 1.78 \mathrm{~mm}$ on the medial side and $13.28 \pm 1.86 \mathrm{~mm}$ on the lateral side. The mean flexion gap measured with the hip in the $45^{\circ}$ flexion position was $13.02 \pm 2.17 \mathrm{~mm}$ on the medial side and $13.12 \pm 2.24 \mathrm{~mm}$ on the lateral side, whereas the value was $12.92 \pm 2.03 \mathrm{~mm}$ and $13.08 \pm 2.29 \mathrm{~mm}$, respectively, when the hip was in the $90^{\circ}$ flexion position. Therefore, no statistically significant differences between the medial and lateral joint gaps were observed regardless of the flexion position. The mean difference in the flexion gap between the $45^{\circ}$ and $90^{\circ}$ hip flexion positions ranged from $0-1.5$ $\mathrm{mm}$ : the mean difference was $0.34 \pm 0.35 \mathrm{~mm}$ on the medial side and $0.40 \pm 0.43 \mathrm{~mm}$ on the lateral side. The medial and lateral flexion gaps for the $45^{\circ}$ hip flexion position were greater than those for the $90^{\circ}$ hip flexion position, but the differences were not statistically significant. In addition, no notable differences were observed in the comparison of the medial and lateral extension gaps, midflexion gaps, and flexion gaps in $45^{\circ}$ and $90^{\circ}$ hip flexion positions (Table 1).

Regarding the radiographic assessment, the mean MAD was $-4.8^{\circ}$ (range, $-8.7^{\circ}$ to $-0.1^{\circ}$ ) preoperatively and $-0.4^{\circ}$ (range, $-2.4^{\circ}$ to $+2.9^{\circ}$ ) postoperatively. The mean PTA was $4.1^{\circ}$ (range, $1.0^{\circ}$ to $6.7^{\circ}$ ) preoperatively and $2.8^{\circ}$ (range, $0.4^{\circ}$ to $6.3^{\circ}$ ) postoperatively. The mean JLTB was $22.15 \pm 3.23 \mathrm{~mm}$ preoperatively and $22.41 \pm 4.12 \mathrm{~mm}$ postoperatively. The changes in the in the PTA and JLTB between the preoperative and postoperative period did not show statistical significance (Table 2).

Table 1. Results of Measurement of Joint Gap Using Navigation System

\begin{tabular}{lccc}
\hline \multicolumn{1}{c}{ Variable } & Medial & Lateral & p-value \\
\hline Extension gap & $12.90 \pm 1.70$ & $13.28 \pm 1.70$ & 0.127 \\
Midflexion gap $\left(\mathrm{knee} 45^{\circ}\right)$ & $12.98 \pm 1.78$ & $13.28 \pm 1.86$ & 0.083 \\
Flexion gap & & & \\
Hip $45^{\circ}$ & $13.02 \pm 2.17$ & $13.12 \pm 2.21$ & 0.435 \\
Hip $90^{\circ}$ & $12.92 \pm 2.03$ & $13.08 \pm 2.29$ & 0.133 \\
& NS & NS & \\
& &
\end{tabular}

Values are presented as mean \pm standard deviation.

NS: no significant ( $p$-value $>0.05$ ).

${ }^{a)}$ Paired t-test ( $\mathrm{p}$-value $\leq 0.05$ considered to be significant).

\section{Discussion}

In this study, the mean medial and lateral flexion gaps in the $45^{\circ}-90^{\circ}$ hip-knee flexion position $(13.02 \pm 2.17 \mathrm{~mm}$ and $13.12 \pm 2.21 \mathrm{~mm}$, respectively) were greater than those in the $90^{\circ}-90^{\circ}$ flexion position $(12.92 \pm 2.03 \mathrm{~mm}$ and $13.08 \pm 2.29 \mathrm{~mm}$, respectively), but the differences were statistically insignificant. In addition, a polyethylene insert change due to notable difference in the flexion gaps between the two hip flexion positions $(\geq 2.5$ $\mathrm{mm}$ ) was not required in any of the patients. Therefore, it is our understanding that the hip flexion position has no major influence on the flexion gap measurement in TKA, and the impact of the thigh weight on the flexion gap can be offset by soft tissue tension.

In TKA, bone resection and soft tissue balancing for lower limb alignment are primary prognostic factors ${ }^{1-3}$. Specifically, the extent of resection of the posterior femoral condyle and the proximal tibia and soft tissue laxity determine the flexion gap size between the tibia and the femur. A flexion-extension gap mismatch could result in pain, swelling, and joint instability in the early postoperative period ${ }^{9,10)}$ and eventually lead to TKA failure in the long-term due to component loosening caused by polyethylene wear $^{11,12)}$.

An appropriate joint gap in the knee can be achieved by proper bone resection and soft tissue balancing based, in general, on the assessment of the extension gap and flexion gap measured in $90^{\circ}$ knee flexion and either the $45^{\circ}$ or $90^{\circ}$ hip flexion ${ }^{4,5)}$. Due to the possible impact of the hip flexion positions on the tension of the surrounding soft tissues, such as the quadriceps muscle and the iliotibial band, and the thigh weight, a controversy can be raised regarding the optimal hip flexion position for precise measurement of the flexion gap in the knee. However, our study results showed that the two hip flexion positions did not result in significant differences in the flexion gap, indicating that neither the thigh weight nor the soft tissue tension has substantial influence on the joint gap at least in PCL substituting TKA.

Table 2. Comparisons between Preoperative (Preop) and Postoperative (Postop) Radiographic Parameters

\begin{tabular}{lrrr}
\hline \multicolumn{1}{c}{ Parameter } & \multicolumn{1}{c}{ Preop } & \multicolumn{1}{c}{ Postop } & p-value \\
\hline Mechanical axis deviation $\left(^{\circ}\right)$ & $-4.82 \pm 1.91$ & $-0.37 \pm 1.09$ & $<0.001$ \\
Patellar tilt angle $\left(^{\circ}\right)$ & $4.10 \pm 1.84$ & $2.84 \pm 1.76$ & 0.069 \\
$\begin{array}{l}\text { Joint line height from tibial } \\
\text { tuberosity (mm) }\end{array}$ & $22.15 \pm 3.23$ & $22.41 \pm 4.12$ & 0.427 \\
\hline
\end{tabular}

Values are presented as mean \pm standard deviation.

${ }^{\text {a) }}$ Paired t-test ( $\mathrm{p}$-value $\leq 0.05$ considered to be significant). 
Knee joint gaps may be associated with the extent of bone resection and soft tissue release, degree of posterior tibial slope, preservation of PCL, and rotation of implants. However, we think that these factors played a minor role in our study focusing solely on the influence of the hip flexion, considering that there was no remarkable radiographic change in the posterior tibial slope and joint line height during the preoperative and postoperative period. In addition, the flexion gap measurement was performed following bone resection and soft tissue balancing; thus, we believe the impact of such factors could be ruled out as much as possible. Knee joint gaps are often estimated with subjective measurement methods. In an attempt to improve objectivity, spacers and tensors are employed by some surgeon $\mathrm{s}^{4,13}$. Tensors require manual application of joint distraction force ${ }^{14,15)}$, and the measurement values can vary depending on the magnitude of the applied force. In addition, tensors may not allow for patellar reduction during joint gap measurement, which may affect the joint gap $\operatorname{size}^{16,17)}$. In contrast, navigation systems facilitate relatively accurate measurements with the patella reduced without application of distraction force. In our study, flexion gaps could be assessed with the patella reduced due to the employment of a navigation system, and the measurement errors could be minimized by using the values derived from the program for analysis.

However, considering that high soft tissue tension can be caused by pre-existing flexion contracture or severe varus deformity, the composition of the study population with only relatively mild deformity may have biased the study outcomes. Thus, we think our results should be confirmed in further studies that involve larger populations.

\section{Conclusions}

There was no statistically significant difference in the flexion gap between $45^{\circ}$ and $90^{\circ}$ hip flexion positions in TKA. The thigh weight and soft tissue tension did not appear to influence selection of the thickness of the polyethylene insert. Therefore, we believe that the hip flexion position $\left(45^{\circ}\right.$ or $\left.90^{\circ}\right)$ duding flexion gap measurement can be determined based on the surgeon's preference.

\section{Conflict of Interest}

No potential conflict of interest relevant to this article was reported.

\section{References}

1. Kelly MA. Ligament instability in total knee arthroplasty. Instr Course Lect. 2001;50:399-401.

2. Naudie DD, Rorabeck CH. Managing instability in total knee arthroplasty with constrained and linked implants. Instr Course Lect. 2004;53:207-15.

3. Krackow KA. Revision total knee replacement ligament balancing for deformity. Clin Orthop Relat Res. 2002;(404):1527.

4. Griffin FM, Insall JN, Scuderi GR. Accuracy of soft tissue balancing in total knee arthroplasty. J Arthroplasty. 2000;15:970-3.

5. Vail TP, Lang JE, Sikes CV. Surgical techniques and instrumentation in total knee arthroplasty. In: Scott WN, Insall JN, eds. Insall \& Scott surgery of the knee. 5th ed. Philadelphia, PA: Churchill Livingstone; 2012. p1042-99.

6. Martin JW, Whiteside LA. The influence of joint line position on knee stability after condylar knee arthroplasty. Clin Orthop Relat Res. 1990;(259):146-56.

7. Sasaki T, Yagi T. Subluxation of the patella. Investigation by computerized tomography. Int Orthop. 1986;10:115-20.

8. Kwon SH, Lee JH, Kim KK. The accuracy of lower extremity alignment in total knee arthroplasty using navigation system: data analysis of 661 cases. J Korean Orthop Assoc. 2009;44:599-603.

9. Unitt L, Sambatakakis A, Johnstone D, Briggs TW; Balancer Study Group. Short-term outcome in total knee replacement after soft-tissue release and balancing. J Bone Joint Surg Br. 2008;90:159-65.

10. Takahashi T, Wada Y, Yamamoto H. Soft-tissue balancing with pressure distribution during total knee arthroplasty. J Bone Joint Surg Br. 1997;79:235-9.

11. Berend ME, Ritter MA, Meding JB, Faris PM, Keating EM, Redelman R, Faris GW, Davis KE. Tibial component failure mechanisms in total knee arthroplasty. Clin Orthop Relat Res. 2004;(428):26-34.

12. Wasielewski RC, Galante JO, Leighty RM, Natarajan RN, Rosenberg AG. Wear patterns on retrieved polyethylene tibial inserts and their relationship to technical considerations during total knee arthroplasty. Clin Orthop Relat Res. 1994;(299):31-43.

13. Laskin RS, Rieger MA. The surgical technique for performing a total knee replacement arthroplasty. Orthop Clin North Am. 1989;20:31-48.

14. Nowakowski AM, Majewski M, Muller-Gerbl M, Valder- 
rabano V. Development of a force-determining tensor to measure "physiologic knee ligament gaps" without bone resection using a total knee arthroplasty approach. J Orthop Sci. 2011;16:56-63.

15. Matsumoto T, Muratsu H, Tsumura N, Mizuno K, Kurosaka M, Kuroda R. Soft tissue balance measurement in posteriorstabilized total knee arthroplasty with a navigation system. J Arthroplasty. 2009;24:358-64.
16. Kim HC, Roh JY, Lee CW, Hong WS. The effect of patellar position on the flexion gap in total knee arthroplasty. J Korean Knee Soc. 2007;19:32-7.

17. Matsumoto T, Muratsu H, Tsumura N, Mizuno K, Kuroda $\mathrm{R}$, Yoshiya S, Kurosaka M. Joint gap kinematics in posteriorstabilized total knee arthroplasty measured by a new tensor with the navigation system. J Biomech Eng. 2006;128:86771. 